\title{
Open Dislocated Bi-Malleolar Ankle Fracture in a Diabetic Treated with the Illizorov Apparatus: A case report in early ambulation and stabilization
}

\author{
by Sutpal Singh, DPM. FACFAS ${ }^{1 \rrbracket}$, Chih-Hui (Jimmy) Tsai, DPM ${ }^{2}$, Albert Kim, DPM ${ }^{3}$, \\ Timothy Dailey, DPM ${ }^{4}$
}

The Foot and Ankle Online Journal 3 (2): 2

The authors describe a case report of a diabetic patient with an open bi-malleolar ankle fracture sustained after a motor vehicle accident that was treated immediately after injury. Treatment included extensive pulse lavage with antibiotic impregnated saline solution and reduction of the fractures using external fixation. Recovery lasted several months, followed by usage of a Pneumatic CAM walker. The external fixator allowed the patient to ambulate throughout the healing process. No internal fixation was utilized. After months of follow-up, there was good healing of the fractures with no infection of the tibia, fibula, and talus. The authors recommend reduction of tibial and/or fibular fracture(s) using the Ilizarov methodology especially in diabetic patients with open fractures and/or contaminated wound.

Key words: Open Ankle Fracture, Gustilo System, Bi-Malleolar ankle fracture, Ilizarov method, diabetes.

Accepted: January, $2010 \quad$ Published: February, 2010

This is an Open Access article distributed under the terms of the Creative Commons Attribution License. It permits unrestricted use, distribution, and reproduction in any medium, provided the original work is properly cited. CThe Foot and Ankle Online Journal (www.faoj.org)

$\mathrm{H}$ istorically, an open ankle fracture commonly equated with much morbidity and mortality. However with more modern therapy, the expected outcome has improved significantly. ${ }^{1}$ The purpose of this article will be to describe a report of a diabetic patient with an open dislocated ankle fracture and the significance of treatment with the use of an Illizarov apparatus. In this article, discussion will focus on the classification, complications, and treatment protocols of open fractures to the ankle joint.

Address correspondence to: Sutpal Singh, DPM. FACFAS. Private practice in Southern California. Email: spsingh@aol.com

${ }^{1}$ Chief Ilizarov Surgical Instructor at Doctors Hospital West Covina. Fellow of the American College of Foot and Ankle Surgeons, Private practice in Southern California.

${ }^{2}$ Chih-Hui (Jimmy) Tsai, DPM, Doctor of Podiatric Medicine (R3). Foot and Ankle Medicine and Surgery, Doctors Hospital of West Covina , (PM\&S-36).

${ }^{3}$ Albert Kim, DPM, Doctor of Podiatric Medicine (R2), Foot and Ankle Medicine and Surgery, Doctors Hospital of West Covina (PM\&S-36).

${ }^{4}$ Timothy Dailey, DPM, Doctor of Podiatric Medicine (R1), Foot and Ankle

Medicine and Surgery, Doctors Hospital of West Covina (PM\&S-36).
The Illizarov apparatus in our case allowed the patient ambulate during the recovery period in attempt to decrease other risks such as infection and osteomyelitis by use of open internal fixation and morbidity associated with prolonged immobility of a limb.

A fracture is considered to be open when there is a disruption of the skin and underlying soft tissues resulting in a communication between the fracture and the outside environment. Open fractures are most commonly classified according to the system developed by Gustilo and Anderson. ${ }^{1,2}$

(C) The Foot and Ankle Online Journal, 2010 

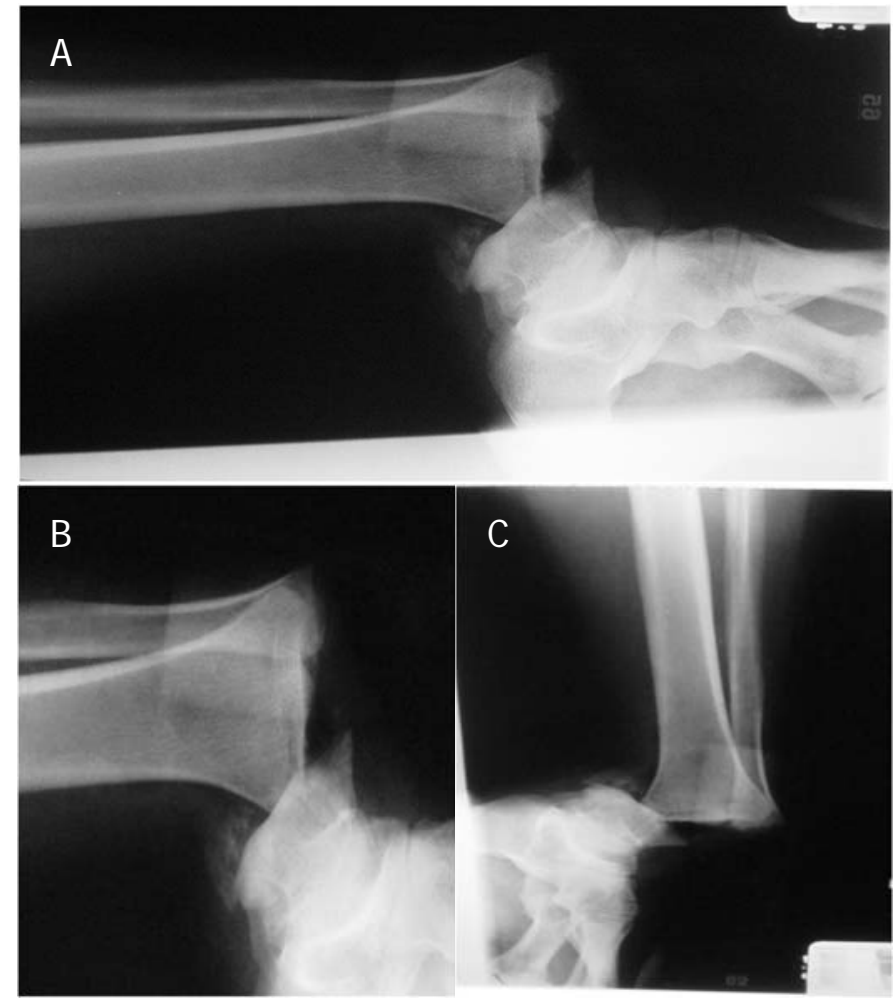

Figure 1A, B and C Variable views of the open ankle fracture.

The classification of open fractures is based on the size of the wound, the amount of soft tissue injury, fracture pattern and correlates with both infection and amputation rates. Type I open fractures are characterized by a clean wound smaller than $1 \mathrm{~cm}$ in diameter, appears clean with a simple fracture pattern and no skin crushing. The fracture can be short, oblique, or transverse. Type II presents with a laceration larger than $1 \mathrm{~cm}$ without significant soft tissue crushing or skin flaps, with minimal periosteal stripping; however, a more complex fracture pattern may result. Type III features a large crush component with comminution. It is larger than $5 \mathrm{~cm}$, highly contaminated with extensive soft tissue injury. These injuries may also be older than six hours. Type III injuries are subdivided into three types: type IIIA which presents with adequate soft tissue coverage of the fracture despite high energy trauma or extensive laceration or skin flaps; type IIIB featuring inadequate soft tissue coverage with extensive periosteal stripping, and finally type IIIC which displays with any open fracture that is associated with vascular injury that requires repair., ${ }^{2,3}$

Patients with open fractures are at risk of complications of acute wound infection and osteomyelitis. The risk of a clinical infection depends on the severity of the injury and ranges from $0 \%$ to $2 \%$ for type-I open fractures, $2 \%$ to $10 \%$ for type-II, and $10 \%$ to $50 \%$ for type-III. ${ }^{4}$ The rate of infection of open fractures is associated with the fracture characteristics, antibiotic therapy variables, and host parameters.

Another variable is the location of the open fracture with tibial open fractures resulting in twice the rates of infection than other areas of the body. ${ }^{4}$ Other possible complications include inadequate soft tissue coverage or extensive soft tissue damage resulting in the failure to heal or even close. This may be exasperated by a compromised neurovascular status of the injured extremity or the development of a compartment syndrome. ${ }^{5}$ Open fractures may also succumb to osseous mal-union or non-union, the loss of function, and even amputation.

Management of the open fracture is dependent upon the following principles: careful and thorough assessment of the patient; initial stabilization; classification of the injury; tetanus prophylaxis; antibiotic therapy; prompt surgical debridement and wound management; fracture stabilization through internal fixation, external fixation, or casting; early bone grafting; timely wound closure; supplemental procedures to achieve healing; and adequate followup. ${ }^{6}$ In any given situation, the best option for fixation depends on a number of factors, including the bone involved, the fracture site, the wound location, and the condition of the patient. The available evidence supports the current trend toward earlier coverage and closure of open fracture wounds. $^{7} \quad$ The ultimate goal of a surgeon when dealing with open fractures is to prevent infection, promote fracture healing, and restore alignment and function. 


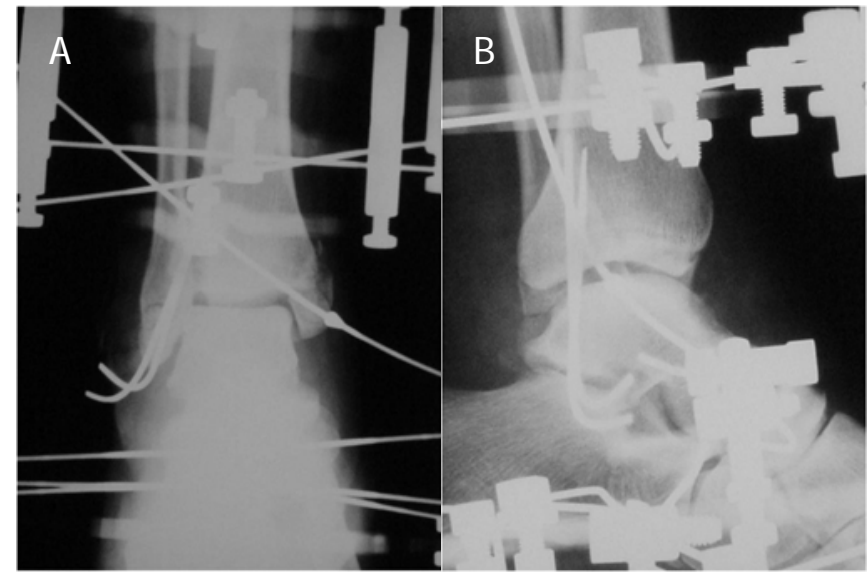

Figure 2 External fixation at the ankle. Note the olive wire reducing the comminuted medial malleolar fracture. (A) Lateral view of the ankle with an External Fixator in place. (B)

\section{Case Report}

A 33 year-old female who had a motor vehicle accident presents with an acute, open, dislocated, bimalleolar fracture of the right ankle. She was immediately transferred to the emergency room. Her past medical history was significant for Type II Diabetes, diagnosed over 10 years ago. She has peripheral neuropathy, with numbness up to the midleg. The rest of the history and review of systems was unremarkable. The right ankle fracture presents to our service wrapped in gauze which is soaked in blood. She did not have a splint on, and the foot is severely dislocated. There is tremendous swelling, but no fracture blisters. Despite the extent of this high impact open fracture, a hand-held Doppler showed that she has good vascular status to the dorsalis pedis and posterior tibial arteries. Her capillary refill is immediate. The open ankle fracture is on the lateral side with the wound measuring approximately $9 \mathrm{~cm} \mathrm{x}$ $5 \mathrm{~cm}$. Even though the fibula, talus and distal tibia were exposed, there is enough skin to close the wound. Uniquely, there is no dirt or any gross contamination noted despite the nature of this accident. X-rays of the ankle indicated that she has a severely dislocated bi-malleolar ankle fracture. (Figs. $1 \mathrm{~A}, \mathrm{~B}$ and $\mathrm{C})$.

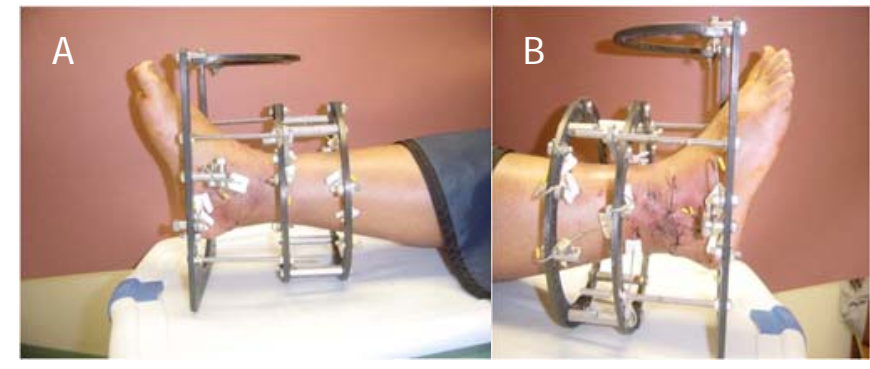

Figure 3 Ilizaorov Frame medial view (A) and lateral view. (B)

The medial malleolus is comminuted. Since the open fracture is less than 6 hours old, she is taken to the operating room immediately in order to reduce the fracture using the Ilizarov frame. The patient is then allowed to ambulate directly after surgery when indicated.

\section{Surgical Technique}

Under general anesthesia, the open wound is cultured for bacterial organism. Afterwards, nine liters of bacitracin and Ancef impregnated saline is used to irrigate the wound. Two tibial rings are applied to the distal tibia and a foot plate is then applied. Both are tensioned appropriately. The foot plate is then manipulated so the fibular fracture and medial malleolar fracture are reduced in anatomical alignment. The foot plate and the tibial rings are then joined together with appropriate rods. Distraction of the foot plate is performed in order to pull the fibula and medial malleolus fractures into better alignment. The fibula is then stabilized using two K-wires while the comminuted medial malleolus is reduced using an olive wire at the largest fragment. The olive wire is inserted from distal-inferior-posterior-medial to proximal-superior-anterior-lateral, attached to the proximal tibial ring and tensioned for compression (Figs. 2A and B). The open wound is then very loosely approximated and packed with iodoform. Several days later, the culture results revealed no bacterial growth. The wound is again irrigated with normal saline and Bacitracin $($ and then completely closed using 3-0 prolene (Figs. 3A,3B,4,5A and 5B). 


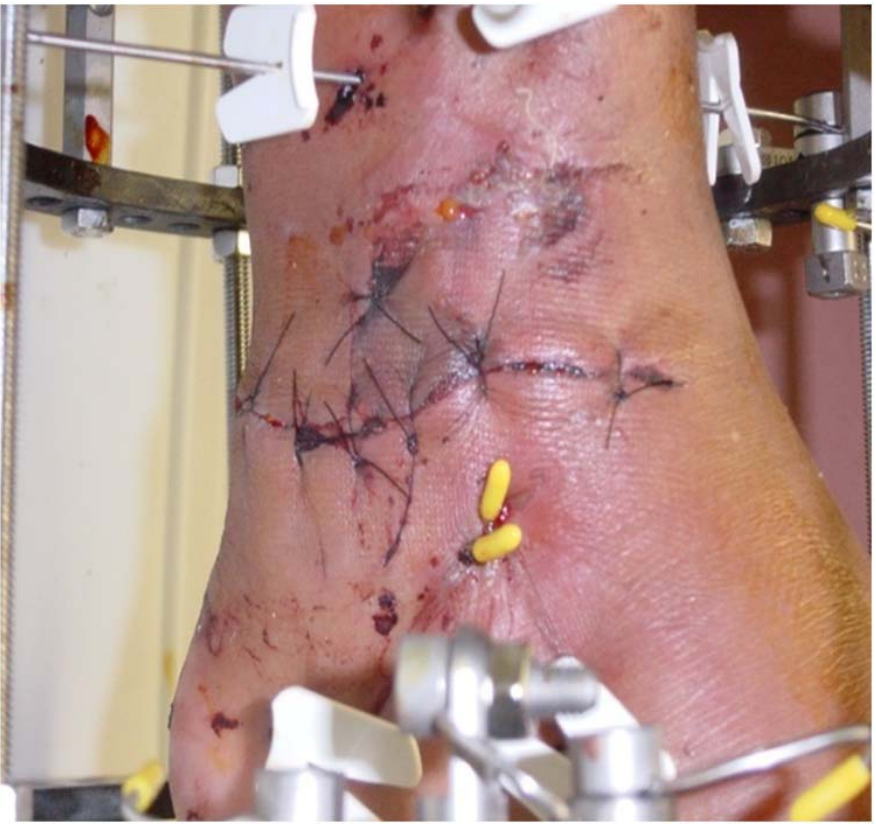

Figure 4 Loose approximation of the open fracture. The iodoform packing has been removed from the open wound.

\section{Discussion}

The complexity of open ankle fractures pose a challenge to many foot and ankle surgeons. By definition, an open fracture is considered contaminated or infected after six hours of no treatment. Very often in a high speed motor vehicular accident, there can be fracture of the tibia, fibula, and/or other part of the foot are present along with an open wound. In this report, we have a patient with a large open wound, bi-malleolar ankle fracture, and exposed tibial, fibular, and talus. The case is further complicated by the patient's diabetes mellitus. However because surgery is performed immediately and the wound is clean with no gross contamination during examination, we were able to utilize the Illizarov apparatus immediately after the accident to fixate and stabilize the open ankle fracture.

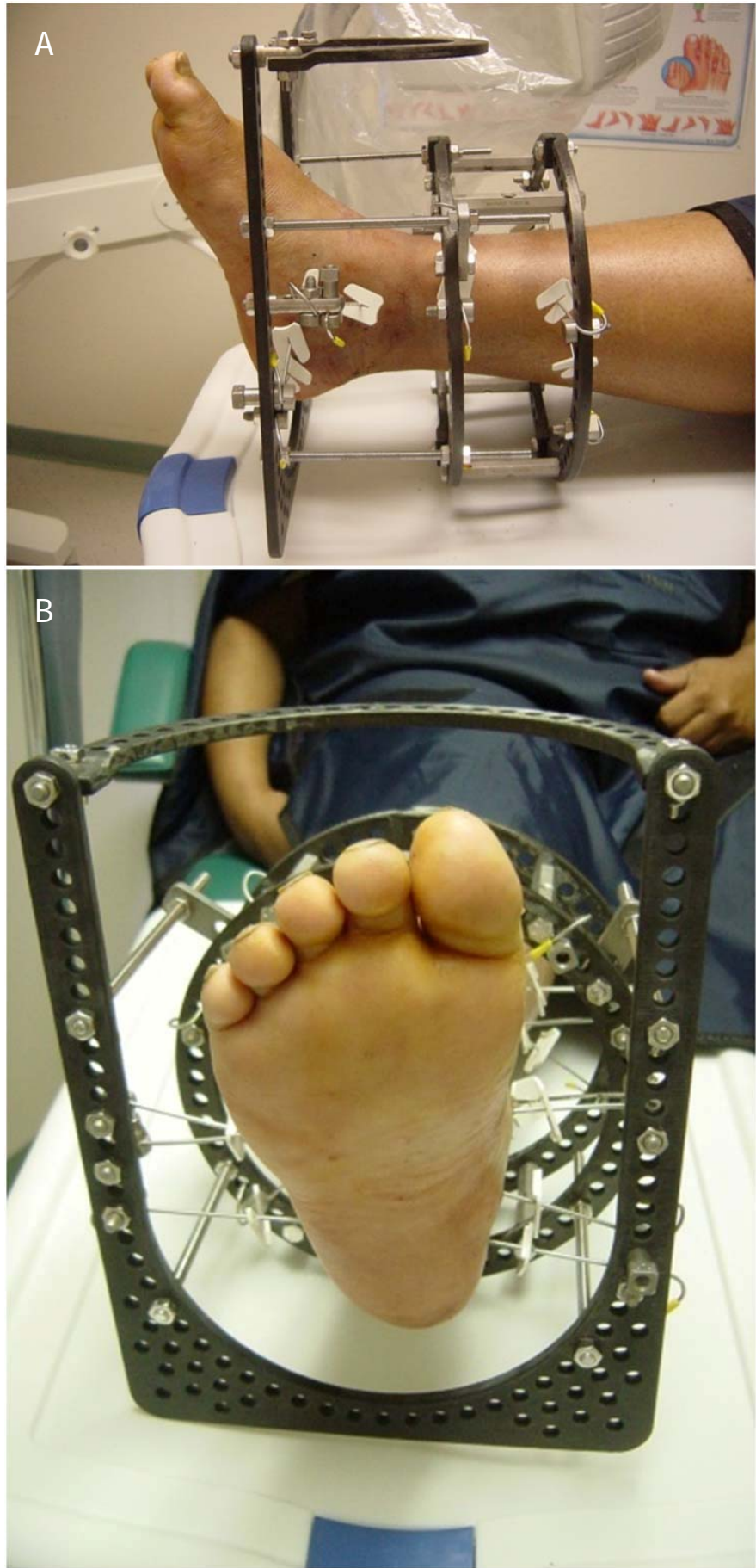

Figure 5 Medial View of the Ilizarov frame several months later. (A) The Ilizarov frame several months later. (B) 


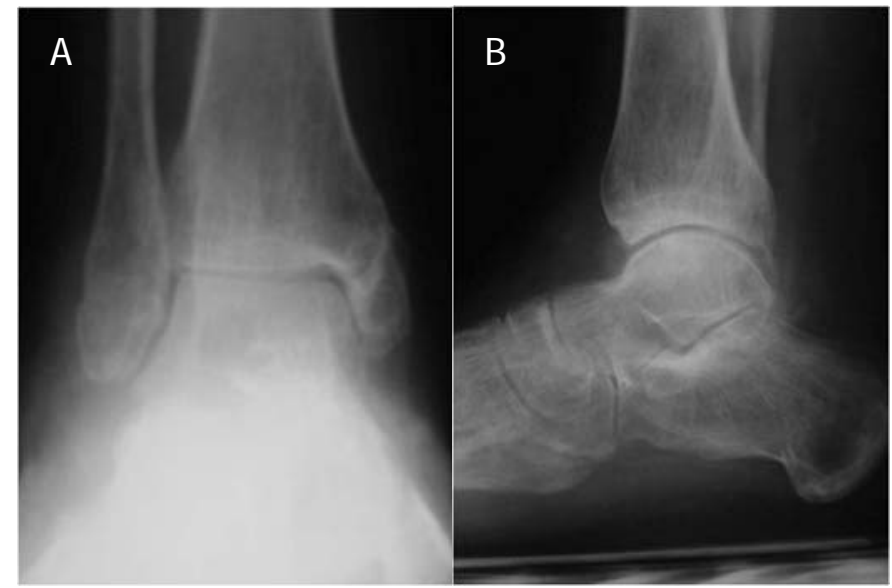

Figure 6 Anteroposterior (A) and lateral view (B) two years after injury.

An external fixator is recommended when a patient has poor bone stock, poor healing potential, open fractures, or fractures with contaminated wounds. ${ }^{8}$ With a high level of morbidity and risk of osteomyelitis, application of internal fixation by itself followed by primary closure of the wound is not indicated. In addition, a larger wound would require a split-thickness skin graft or benefit from healing by secondary intention. Using an external fixator is not only minimally invasive, but it also allows the surgeon to stage the treatment appropriately. The patient can also benefit from being able to bear weight. Any wounds after surgery can easily be viewed and treated with an external fixator. This is of course, contraindicated when using a cast.

The complications associated with the use of an external fixator include pin tract infection and wire failure. These can be mitigated and appropriately treated with antibiotics and pin care to help prevent infection at these sites. The above patient is classified as having a Gustillo type IIIA. She has a large open wound with adequate soft tissue for coverage. She also has a severe ankle dislocation, bi-malleolar ankle fracture, and exposed tibia, fibula and talus. The external fixator was removed after 3 months. She then had a pneumatic cam walker applied. A two year follow-up showed that her ankle healed in an anatomical position with good range of motion (Figs. $6 \mathrm{~A}$ and $\mathrm{B})$.

\section{Conclusion}

This case report shows the advantages to using external fixation for an open ankle fracture secondary to a motor vehicle accident. Use of external fixation has many advantages, as explained previously. The goals of open fracture surgery are to prevent infection, promote fracture healing, and restore function. A detailed history and physical is essential in these type of complicated cases. The surgeon must decide which surgical option is going to meet specific goals.

\section{References}

1.Patrick JH, Smelt GJ: Surgical progress-100 years ago. An assessment of Listerism at St. Thomas's Hospital, London. Ann R Coll Surg Engl 59: 456 - 462, 1977.

2. Gustilo RB, Anderson JT: Prevention of infection in the treatment of one thousand and twenty-five open fractures of long bones: retrospective and prospective analyses. J Bone Joint Surg 58A: 453 - 458, 1976.

3. Gustilo RB, Mendoza RM, Williams DN: Problems in the management of type III (severe) open fractures: a new classification of type III open fractures. J Trauma 24: 742 -746, 1984.

4. Patzakis MJ, Wilkins J: Factors influencing infection rate in open fracture wounds. Clin Orthop Relat Res 243: 36 - 40, 1989.

5. Blick SS, Brumback RJ, Poka A, Burgess AR, Ebraheim NA: Compartment syndrome in open tibial fractures. J Bone Joint Surg 68A: 1348 - 1353, 1986.

6. Zalavras CG, Marcus RE, Levin S, Patzakis MJ: Management of Open fractures and subsequent complications. J Bone Joint Surg Am 89A: 883 - 895, 2007.

7. Okike K, Bhattacharyya T: Current concepts review: Trends in the management of open fractures. J Bone Joint Surg 88A: $2739-2747,2006$.

8. Molloy A, Roche A, Narayan B: Treatment of nonunion and malunion of trauma of the foot and ankle using external fixation. Foot and Ankle Clinics Sept: 563 - 587, 2009. 